\title{
Review on Recent Development in Environmental-friendly EDM Techniques
}

\author{
Nishant Kumar Singh ${ }^{1 *}$, K. K. Singh ${ }^{2}$ \\ ${ }^{1}$ Research Scholar, Department of Mechanical Engineering, ISM, Dhanbad, India \\ 2 Department of Mechanical Engineering, ISM, Dhanbad, India
}

\begin{abstract}
The electrical discharge machining (EDM) is unitary of the widely used unconventional machining because of its ability to cut very hard material engendering high dimensional accuracy as well. In thermo-electric process, control sparks generation between electrodes causes material removal; however, application of hydrocarbon oil based dielectric is an issuance of environmental disruption. To rectify this problem, replacement of dielectric is main concerns in EDM research. This paper highlights Dry-EDM, Near-Dry EDM and EDM in water, which is conceived as an environment amiable alteration in the oil EDM process. The work gives a thorough review of Dry, near-dry EDM and EDM in water as a process, where the target is to endeavor dielectric fluids that can be substituted bypassing hydrocarbon oil. It is perceived that water and gas based dielectrics could take over oil-based fluids in die sink applications. Novel technological advances in dry EDM machining processes, which deliberate the relatively advanced stage of a technology in to the area of academic and industrial research is briefly reviewed. An outline of the prospective trend of reviewing is intimate in the last fragment.
\end{abstract}

Keywords: EDM, Dry-EDM, Near-dry EDM, UAEDM

\section{Introduction}

Electrical discharge machining (EDM) is most widely used non-conventional material removal processes. Often find application in manufacturing of mould, die, automotive, aerospace and surgical components. It has a special power to utilize thermal energy to machine electrical conductive parts of high hardness [1]. EDM eradicates problems of mechanical stresses, chatter and vibration while machining, as it does not make direct contact with the electrode and the work piece [2]. EDM has considerable superiority over conventional machining in relation to manipulating workpiece of hard materials and complex shapes [4]. Nevertheless, there is an abundance of deprivations, as it amalgamates environment pollution and being detrimental to the cognitive process [5]. EDM operations extensively use kerosenebased dielectric liquid. So, for the perseverance and the competency of the EDM process, the use of liquid is pivotal because liquid effectively provides a cooling medium in a discharge gap, thereby provide significant roles during material removal mechanism [6-9]. During the EDM process, coal oil-based dielectric liquid decomposes and produce vapor, which is harmful to the operator [10]. Nevertheless, when hydrocarbon oil is used, health, safety and the environment become important aspects [11]. Present research focus on development of no-polluting 
technique, which protect the environment and facilitate substantial high MRR, low TWR, surfaces accuracy and minimum roughness values [12].

\section{Dry EDM Machining}

In 1985 Ramani and Cassidenti, noted in a short technical paper by NASA, use of gas based EDM. Argon or helium gas was applied as a dielectric for drilling a hole by a tubular copper electrode [13]. However, in 1997 Kunieda and Yoshida proposed new machining method known as EDM in gas. They propose to decrease pollution by using gas rather than kerosene based dielectrics. Afterwards, it is being studied as method of good prospects [14].

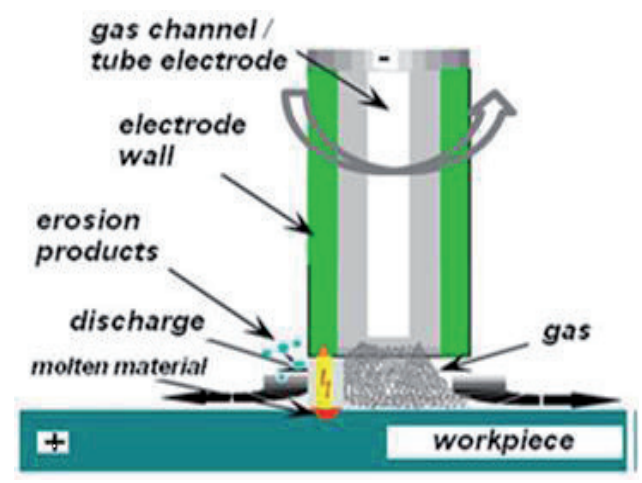

Fig. 1: The principle of dry EDM [12].

To diminish the pollution and production of vapor during EDM machining using liquid dielectric, the EDM usual procedure was further processed. In dry EDM, compressed, gas or air passes through a thin walled tubular pipe, where compressed gas cools the inter electrode gap and thus gets rid of debris from the gas $[14,15]$. Still, Dry EDM is considered as an environmentally beneficial technique because of the absence of mineral oil-based liquid dielectric and environmentally harmful oil-based dielectric wastes are not raised. Likewise, the procedure does not pose a health hazard since toxic fumes are not generated during machining. Additionally, absences of mineral oil-based dielectrics drastically reduce fire hazards during the procedure. Most likely, advantages of DEDM process are negligible tool wear, low residual stresses and higher precision. For machine makers and machine users, practical application of the DEDM process endeavor many advantages like simplicity in machine build- ing, since does not require sophisticated dielectric circulation and cooling scheme, which contributes to manufacturing and material price reductions. Considering concrete benefits of dry machining processes, as shown in Figure 2, firms and researchers involved in the evolution of electro discharge machining primarily aiming towards minimizing the use of hydrocarbon dielectric fluids, either by replacing with gas, pure water or water-emulsion solutions [16]. Although method is really encouraging, but needs, furthermore, exhaustive investigation before it can see widespread application at an industrial scale.

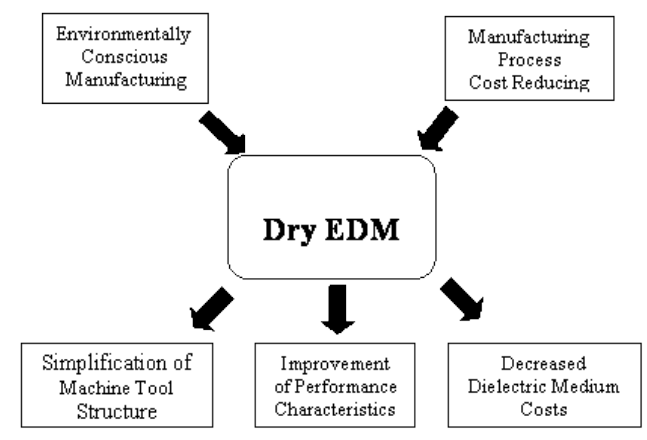

Fig. 2: Advantages of dry electro discharge machining [16].

\section{Systematic Investigation of the Dry EDM Process}

An organized investigation of dry EDM is necessary for interpretation to the process, with some fundamental input as well as output factors. From figure 3 , it can be seen that, some of the inputs factors consider are the characteristics of the dielectric fluid, in particular, electrical parameters and machining parameters. For output parameters, the underlying factors are material removal rate; tool wear rate, the surface roughness, the wholeness of the surfaces and pollution propagated by the procedure.

This paper focused on recent research initiatives carried out by researchers relevant to environmental aspects thereafter predicting EDM performance by using modeling technique. The specific topic now foresees work carried out by researchers and aftermath of research. Development in dry EDM is presented in following divisions based on the (1) Metal removal rate and Tool wear rate (2) Surface 
roughness and over cut (3) Surface Integrity and (4) breakthrough techniques.

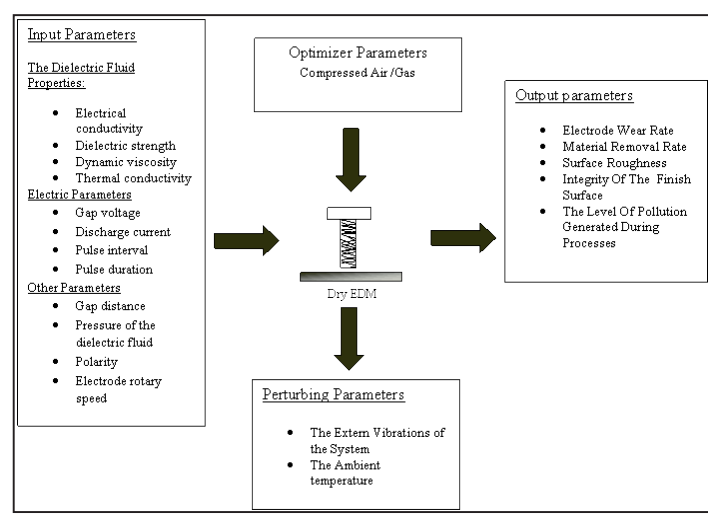

Fig. 3: Factors for systemic analysis of the Dry EDM process [17].

\subsection{Metal Removal Rate and Tool Wear Rate}

Kunieda et al. [14] in 1991 demonstrated new machining method to enhance EDM performance by accumulation of oxygen gas in a discharge gap. It is found that metal removal (MRR) gets increased due to the occurrence of more frequent discharge and enlarged discharge carter. Further, in 1997 Kunieda et al. [15] find that the removal of molten and evaporated work piece material gets increased by using compressed gas flow through a pipe tool electrode. The removed material solidifies and does not remain attached along the airfoil of the work piece as well as a tool electrode because application of the gas flows. Findings suggest that a $3 \mathrm{D}$ shape can be machined by using the NC tool path. Yoshida and Kunieda [18] in 1999 studied tool wear in dry EDM and are on view that TWR is very negligible for most of the pulse duration. This is only because of molten work piece material associated with tool and protects tool wear. Zhan Bo et al. [19] studied the effect of process parameters and investigated the possibility of 3D surface machining in dry EDM. They found that tool wear increases slightly on rotational speed increases. When pulse duration is $25 \mu \mathrm{m}$, optimum combination between depths of cut and gas pressure result in maximum MRR and minimum tool wear. Yu et al. [20] investigated the effectiveness of the dry EDM method in the machining of cemented carbide. High-velocity oxygen gas was applied as the dielectric. Further, dry EDM performance was compared to oil EDM and oil EDM milling. The finding indicates that dry EDM, milling produces the smallest form deviation due to a very low tool wear ratio. The machining speed in dry EDM is higher than for oil milling, EDM but lower than the oil die-sinking EDM. Zhang et al. [21] stated that EDM efficiency gets increased by using ultrasonic vibrations in gas mediums. Results indicated that, open voltage, pulse duration, the amplitude of ultrasonic actuation, the discharge current, and the lessening of the wall thickness of electrode pipe are the significant factor for increasing the material removal rate. Besliu et al. [12] studied dry EDM and performed experiments using liquid as well as the compressed air dielectric. Results showed that in the dry EDM process, electrode tool wear is better than wet EDM during particular operating conditions. Saha and Choudhury [23] studied dry electrical discharge machining and performed a parametric analysis with tubular electrode. Experiments were implemented by utilizing air as the dielectric. Discharges current, pulses on time, duty cycle, gap voltage, air pressure and spindle speed were the controllable process variables. Result show that current, duty factor, air pressure; spindle speed was the significant factor effecting MRR. It also indicated that, TWR is independent of input parameters and increases slightly. Xu et al. [24] used tool electrode ultrasonic vibration assisted electrical discharge machining in the gas mediums. They studied; EDM machining of the cemented carbides workpiece and MRR obtained in EDM in gas as well as ultrasonic vibration assisted gas medium. The finding suggests that by applying ultrasonic vibration, material removal rate increased greatly. It further suggests that in case of ultrasonic vibration assisted machining for a particular discharge pulse-on time MRR was found substantially higher. Puthumana and Joshi [25] used electrodes having peripheral slots for efficient debris disposal and to enhance the MRR; peripheral slots accommodate more space in the flow of dielectric. The analysis of the results indicated that discharge current, gap voltage, rotational speed and pulse of time were the significant factors affecting the metal removal rate in the dry EDM process. In addition, the use of slotted electrodes significantly reduced the attachment of debris particles from the electrodes, and the electrode wear rate. Kunieda et al. [26] improved dry EDM machining performance by controlling the gap distance, using piezoelectric actuators. A simulator was used to study the effects of the piezoelectric actuator 
on metal removal rate and machining stability of dry EDM. Roth et al. [27] analyze the significance of oxidizing gas on the stability of a dry electrical discharge machining process. Finding suggested that the material removal rate minutely affected by high-temperature energy from the oxidation and that the main difference between oxygen and less oxidizing gases is to come up in different stability and time efficiency to the operation. Roth et al. [28] in another research studied the material removal rate and breakdown behavior during the process for different tool electrode and workpiece materials. The finding suggests that the discharge behavior had a prerogative on the material removal rate on the workpiece material. Joshi et al. [29] investigated material removal rate in dry electrical discharge drilling. Final results indicated that the material removal rate significantly influenced by discharge current, gap voltage and rotational velocity. In most of the experiments, TWR found almost zero. They analyzed wear characteristic of a single discharge for both dry EDM process and conventional liquid dielectric EDM process. The outcome shows that larger MRR and crater radius obtained at low discharge energies, for a single discharge in dry EDM as compared to that of traditional liquid dielectric EDM.

\subsection{Polarity, Overcut and surface roughness}

Recently, Li et al. [30] suggested that to constrain discharge points to dissipate in the gap a fixed gas pressure was a prerequisite to consolidate deionization in dry EDM. To confirm the machining process steadfast at the spark discharge state. It was recommended that positive polarity to be used in dry EDM since electrodes manipulates prominent roles in collision and ionization. Zhang et al. [22] used ultrasonic to improve the efficiency in electrical discharge machining (EDM) in a gas mediums. The experimental results indicated that, the surface roughness was increased with respect to the growth of the open voltage, the pulse duration, and the arc current. Saha and Choudhury [23] studied dry electrical discharge machining and performed a parametric analysis with tubular electrode. Outcomes show that current, duty factor, air pressure; spindle speed was the prominent factor affecting surface roughness. Zhang et al. [31] performed experiments to get a model to estimate roughness of the completed surface.
Results showed that surface roughness increases for increase of gap voltage, discharge current and pulse duration. Curodeau et al. [32] performed automated polishing of tool cavity using thermoplastic electrode and air as a dielectric. Results showed surface finish improved from $44 \mu$ Ra to $36 \mu$ Ra. Besliu et al. [12] studied dry electrical discharge machining and find that the errors of the circular shape in a cross section through the hole may be reduced by rotation of the electrode tool.

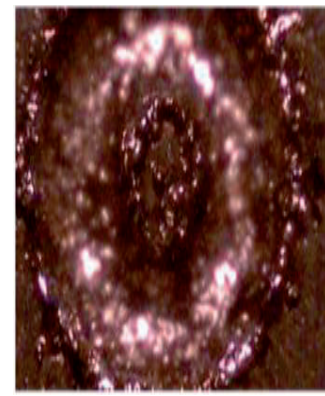

(a)

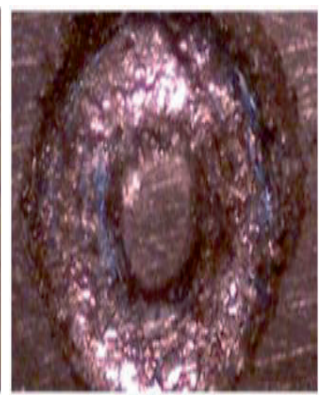

(b)
Fig. 4: (a) Hole obtained using the liquid as dielectric; (b) Hole obtained using air as dielectric [12].

\subsection{Surface Integrity and Modeling Techniques}

Domenico Umbrello [34] performed experiments to analyze formations of white layers during machining of hardened AISI 52100 steel under dry and cryogenic cooling conditions. They found that white layer is partially reduced or can be eliminated for the certain process parameters and cryogenic cooling condition. Govindan and Joshi [35] presented an analysis of micro-cracks on machined surfaces in dry EDM and investigated the effect of process parameters on crack formation using the observations under SEM. Finding suggests that the micro-crack formation is best interpreted in terms of average crack length. Analysis of the results shows that the pulse off-time, discharge current, gap voltage and electrode rotation speed significantly affect the average crack length in both wall and bottom regions of the machined hole. A comparison of crack formation with the liquid dielectric EDM shows that the densities of micro-cracks and average lengths were lower in case of dry EDM. Teimouri and Baseri [36] used back propagation neural network model to correlate the inputs and outputs of the dry EDM process. Gap voltage, pulse current, pulse-on time, duty factor, air intake pres- 
sure and rotational speed of the tool, adopted as an input factor, and material removal rate and surface roughness as an outputs' factors. In optimization stage, single objective optimization was performed to determine the optimal factors related to each production. In order to determine the best solutions for higher metal removal rate and lower surface roughness, a multi-objective optimization was applied. They indicate that a predictive model can be applied to calculate the dry EDM process effectively. It further advises that the ABC algorithm for can also used for the optimal solution sets. Skrabalak and Kozak [17] presented results of simulation and mathematical modeling of the material removal rate of electro discharge milling process with compressed air as a dielectric. The finding hints that in case of DEDM milling, with thin layers the problem of particles attaching the electrode is negligible, as the elimination of the atoms from the working gap is relatively soft. They suggest that, in case of machining at the micro-scale DEDM milling process is more useful than EDM, milling in kerosene, since the tool wear ratio is more precise in case DEDM milling process.

\subsection{Innovative techniques to improve dry machining process}

\section{a. Dry Ultrasonic Vibration, Electrical Discharge:}

Zhang et al. [22] proposed a new advanced method which is experienced as an ultrasonic vibration, electrical discharge (UEDM) machining in gas. The finding indicates that the enhancement of metal removal rate is due to increase in open voltage, pulse duration, amplitude of ultrasonic vibration and decrease of wall thickness of the tube. They further suggested that MRR might be raised by using oxygen gas rather than air as a dielectric. In order to increase the MRR, they introduced the concept of ultrasonic vibration [21]. In other research, Zhang et al. [22] find that for same surface roughness, MRR with the UEDM in gas is less than the conventional EDM but nearly two times than EDM in gas.

\section{b. Dry EDM, milling:}

Kunieda et al. [37] proposed the Dry EDM, milling technique to improve the dry EDM performance. Results show that the metal removal rate of quenched steel obtained by dry EDM, milling was approximately equal to that of high-speed milling. Skrabalak et al. [38] represent the results of the subject areas in the field of dry electro discharge machining. The paper covers comparison, and influence on machining performance, of gas supply method: through electrode and from outside of the electrode, influence of gas pressure, flow rate and rotational speed of the electrode. Results suggested that EDM, milling process with air and sulfur hexafluoride is very effective for micro machining of complex cavities and shapes, and due to the negligible tool wear ratio, this process is more precise than EDM milling in kerosene.

\section{c. Near dry EDM process:}

Hu et al. [39] investigated the near dry milling electrical discharge machining (EDM) for the postprocessing operation of Satellite alloys. Findings indicate that the machining performance is powerfully affected by discharge peak current rather than the other ingredients. They further suggested that, higher discharge current caused a higher MRR, lower TWR and higher surface roughness. Kao et al. [40] investigated the near dry electrical discharge machining (EDM) process using a mixture of water and air as the dielectric fluid. They evoke that for less debris deposition and higher material removal rate; a keener cutting edge may be practiced. At low discharge energy near dry EDM has a higher material removal rate and brings forth a smaller gap distance as compared to wet EDM. They produced a mathematical model to correlate the water-air mixture's dielectric strength and viscosity to the gap distance conceited than the gap distance consists of the discharge distance and material removal depth. Tao et al. [41] investigated a neardry EDM, milling method to obtain a mirror-like surface finish. In this method, liquid-gas mist mixture as the dielectric delivered through a rotating tubular electrode. Results show that at the low discharge energy input near-dry EDM exhibits good machining stability and smooth surface finish. It was indicated that the surface finish is expected to be further thinned out in near-dry EDM by reducing, the pulse duration.

Tao et al. [42] further investigated the dry and near-dry electrical discharge machining (EDM) milling for a superior surface finish for roughing and finishing operations in order to attain a high material removal rate (MRR). For high MRR oxygen gas and copper, electrode is selected in case of dry EDM and in case of near-dry EDM the nitrogenwater mixture and graphite electrode for fine sur- 
face finish. Near-dry EDM exhibits the advantage of good machining stability and surface finish at the lowest discharge energy input. To improve the surface finish in near-dry EDM Lower pulse duration and minor discharge current are diagnosed as key factors.

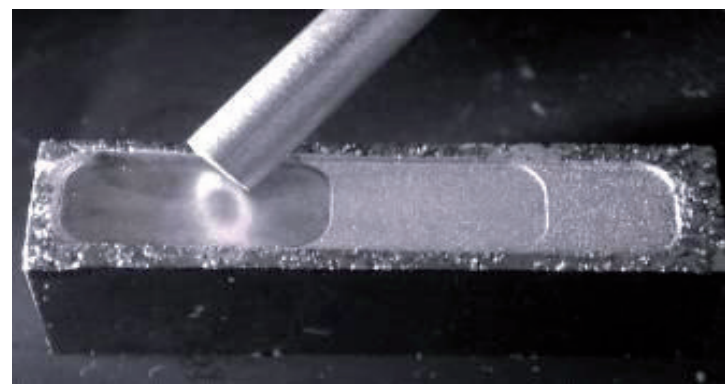

Fig. 5: Illustration of the mirror-like machined surface [41].

\section{d. Using pulsating magnetic field:}

S. Joshi et al. [33] proposed a hybrid dry EDM process for improving process performance, process was implemented in a pulsating magnetic field.

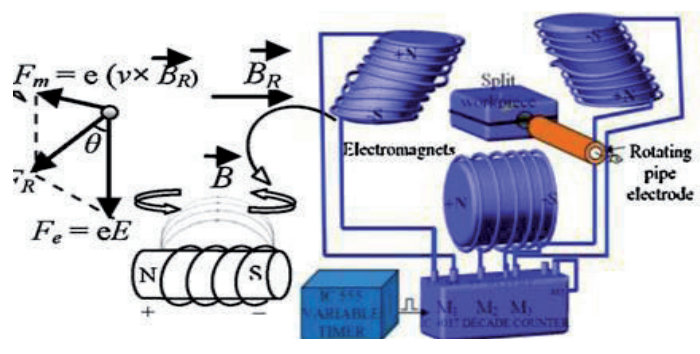

Fig. 6: Schematic of pulsating electromagnetic field application [33].

In this work, the pulsating magnetic field was applied tangential to the electric field for increasing the movement of electrons and the stage of ionization in the plasm. It was found that the application of the magnetic-field induces a higher transfer of thermal energy to the workpiece hence melting and material removal rate in dry EDM is improved considerably. Solutions proved that by application of magnetic field metal removal rate increased by $130 \%$ and almost zero tool wear when compared to the dry EDM process without the magnetic domain. The scanning electron microscopy (SEM) was applied to illustrate improvements in surface quality.

\section{e. Using two generator modes:}

Liquing et al. [43] employ the ISO-frequency mode and the ISO-pulse mode to investigate the machining operations of dry EDM. Results indicate that the metal removal rate and surface roughness value using the ISO-frequency mode or higher than that of the ISO-pulse mode in dry EDM. Under the isopulse mode, MRR and SR present an approximately linear increase with an increase with the pulse width. It was discovered that a high frequency and narrow pulse generator with a high opening voltage might be suitable for dry EDM under a certain circumstance.

\section{f. Approach for gap control and prevent leakage of dielectric mist from the electrode:}

Fujiki et al. [44] suggested a new gap control approach for five-axis milling using near-dry EDM. This new gap controller enables the electrode to retract it in the way of its orientation and causes a more efficient enlargement of the discharge gap leading to faster recovery of average gap voltage. When the electrode retracted in its axial direction, EDM performance was improved. Although on that, point was no improvement in the tool electrode wear ratio and surface roughness, but material removal rates increased by 30\%. Further Fujiki et al. [45] proposed another scheme to prevent leakage of dielectric mist from the tubular electrode it was dissimilar from the conventional end milling process due to the difference in material removal mechanism. They derived relations for tool positions and orientations to engage the electrode into the workpiece, machining of workpiece edge, minimum lead angle to machine a curved surface, and minimum and maximum path interval in order to prevent the mist leakage from the tubular electrode. This written report also discovers that, due to the tool wear and crowning of an electrode tips; it is difficult to accurately define the minimum path interval which will cause the mist leakage.

\section{g. Using cryogenically cooled workpieces:}

Liquing et al. [46] proposed two new dry EDM techniques, namely oxygen-mixed dry EDM and dry EDM with cryogenically cooled workpieces, with the aim of increasing MRR and surface integrity. The results indicate an increment in the MRR for both the oxygen-mixed EDM and the cryogenically cooled workpiece technique. It was found that surface roughness value was smaller in case of a cryogenically cooled electrode. However, oxygenmixed air achieved a high MRR, and that MRR in- 
creases with oxygen content in a two-gas mixing.

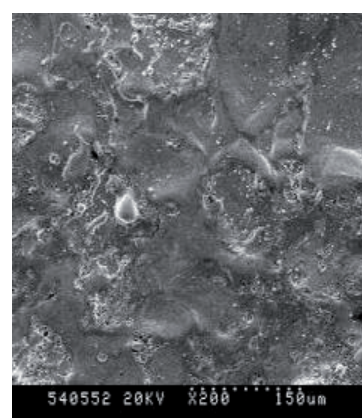

(a) Uncooled

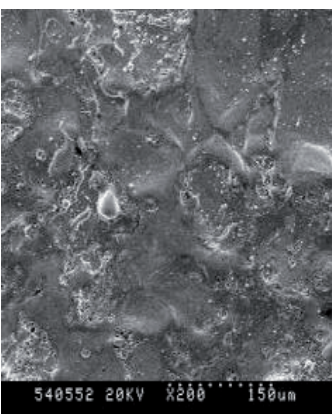

(b) Cooled
Fig. 7: Surface topography comparison of uncooled and cooled workpieces [46].

Dry EDM with cryogenically cooled workpiece was also recorded to ameliorate both the MRR and SR at the chosen experimental conditions. The MRR was improved nearly 30-50\%, and SR approximately 1 to $10 \%$, over what could be achieved with uncooled pieces. An enhanced ejection of debris in this approach was suspected to be the main reason for the improvements over uncooled EDM experiments.

\section{h. Nanoscale electro-machining (EM):}

Malshe et al. [47] give an experimental investigation and delineation of a novel technique of nanoscale electro-machining (EM) in the atmospheric air, named dry nano-EM, by using scanning tunneling microscopy (STM) as the platform for nanomachining. Established on the reflections, they revealed that field-induced evaporation due to intense heat generated at the gap width is the primary mechanism of material removal in dry nano-EM. The experimental results prove that dry nano-EM is capable of fabricating consistent nanofeatures with good repeatability and the mass of material removal increases significantly almost linearly with increasing number of features machined and machining time, indicating the consistency in the proportions of the nano-features. Further, Malshe et al. [48] introduced a comparative work between the wet and dry nano-EM processes based on process mechanism, machining performance, consistency and dimensional repeatability of these two procedures. It was reported that the material removal mechanism of wet nano-EM was associated with field emission-assisted avalanche in nano-confined liquid dielectric, whereas, the material removal mechanism in dry nano-EM was associated with field-induced evaporation of material. The differences also were discovered during the machining operation, proportions of the machined features and repeatability of the nanoscale machined features. The self-tip-sharpening process with the continuation of machining had added several advantages to dry nano-EM over wet nano-EM in terms of dimensions of the nanoscale features, repeatability and machining performance. Zhang et al. [49] proposed powder mixed nano-dry EDM (PMND-EDM) method to improve MRR effectiveness. Outcomes indicate that in PMND-EDM, MRR was influenced by peak current, pulse on time, pulse of time, flow rate, powder concentration, tool rotational speed, and air pressure. Further orthogonal experiment reveals that peak current, pulse on time, and flow rate caused an important influence on MRR.

\section{Use of Water Based Dielectric for EDM}

Comprehensive explorations of the published research paper on the role of water-based dielectrics for the concluding 30 years are insured in the next departments.

\section{a. Effect of water based dielectric on productivity:}

The metal removal rate and electrode wear is lower in case of water as a dielectric as compared to hydrocarbon oil as a dielectric in die sinking EDM. Use of deionized water or even tap water may result in higher levels of material removal rate in some special cases like when brass electrode at negative polarity is used. Erden and Temel [51] showed that machining of steel workpieces with a negative brass electrode in deionised water, resulting a higher material removal rate and lower electrode wear, when compared the same operation in hydrocarbon oil. Jaswani [52] investigated the performances of kerosene, distilled water, and found that when high pulse energy was used machining in distilled water resulted in a lower tool wear and a higher material removal rate than in kerosene oil. It was, likewise, noted that with distilled water surface, finish was better, although the machining accuracy was poor. Jilani and Pandey [53] reported that with the tap water superlative machining rates may obtaine, an almost zero TWR may be achieved when copper tool with negative polarities is used while machining in water. For surface roughness ranging from 40 to $60 \mu \mathrm{m}$, the public presentation 
of tap water was better than distilled water and hydrocarbon oil, for pulse durations less than $500 \mu$ s.

To raise the effectiveness of deionised water some authors suggested to mixed organic compounds such as ethylene glycol, glycerin, polyethylene glycol 200, polyethylene glycol 400, polyethylene glycol 600, dextrose and sucrose in deionised water. Koenig and Joerres [54] found that when forming with long pulse durations, high pulse duty factors and discharge currents, highly concentrated aqueous glycerin solution has an advantage as compared to hydrocarbon dielectrics. Highly concentrated aqueous glycerin solution with graphite electrodes when compared with hydrocarbon oil resulted in higher material removal (40\%) and lower tool wear (90\%). Konig et al. [55] reported that working mediums had a considerable significance for the metal removal process. Under critical conditions, the erosion process in which water is used as a dielectric possesses higher thermal stability and much higher power allowing much larger gains in the MRR. Konig et al. [56] most recently reported that for roughing and finishing machining operation water-based dielectrics with a glycerine accumulation ranging from 50 to $60 \%$ are suitable for machining of large areas such as forging dies and an enhancement in the metal removal rate, approximately $100 \%$ can be accomplished. Masuzawa et al. [57] reported that for a better material removal rate, dielectric containing an organic compound having larger molecular weights was preferred. Results suggest the possibility of advanced uninflammable for dielectric for EDM by introducing an organic solution in water. Machining characteristics of polyethylene glycols with water is competitive with conventional EDM oil.

Liu et al [59] used an oxygen-mixed water-in-oil emulsion as the dielectric in die-sinking electrical discharge machining. Results showed that by mixing oxygen into the water-in-oil emulsion the material removal rate improved highly and the relative electrode wear ratio reduced significantly. It was, likewise, reported that with this oxygen-assisted machining method, recast layer was much flimsier. Further, Liu at al. [60] proposed water in oil emulsion as the operating fluid. Statistical analysis to the results shows that discharges current and water content of the emulsion significantly influenced the machining performance of sinking EDM. It was noted that both MRR and EWR decrease with increasing temperature of the emulsion. Results suggested that water in oil emulsion can be used as the working fluid of sinking EDM and alleviated the environmental impact on the operation. Medellin et al. [61] performed an experiment using different types of water (tap water, deionized water, and mixtures of tap and deionized water) to evaluate the EDM performance of D2 tool steel. The results showed that with a mixture of 75 per cent tap water, and 25 percent deionized water as the dielectric, the maximum material removal rate (MRR) and the minimum tool wear rate (TWR), is achieved while, the inferior out-comes are recited when deionized water is used as the dielectric.

For economic and ecological prospective commercial water-based, fluids like Elbolub, Vitol QL and lonorex 500 plus are used in the production of moulds and dies. Dunnebacke [62] reported that in roughing operations, material removal rate achieved with Elbolub has been 2-three times higher than that achieved with hydrocarbon oil. It was also reported that for graphite electrodes, using Elbolub as the dielectric material removal rate was high, but had higher wear than that seen when machining with oil. Dewes et al. [63] investigated the operation of different dielectrics on the EDM of Inconel 718 and reported that deionize water had a lowest material removal rate. Ionorex and BP180 had a similar removal rate, but BP180 had a higher value of relative electrode wear. Karasawa and Kunieda [64] have compared the effect of use of side jet, and submerging the workpiece and the electrode into the dielectric tank, using water-based dielectric Sodick VITOL-QL. The result showed that due to better flushing conditions; the material removal rate obtained with the side jet was $20 \%$ higher than that of the submerged method.

\section{b. Effects of water based dielectrics on surface integrity:}

Appearance and surface roughness of the machined workpiece with water-based dielectrics and hydrocarbon oil are rather dissimilar. Deionize water usually has oxides on the machined surfaces and lower values of surface roughness while hydrocarbon oil has a contaminated appearance with carbon atoms inside the craters [51, 54, and 58]. Pillans et al. [65] reported that metallurgical alterations and alterations in the mechanical properties of the workpiece occurred. Since EDM 
sparks temperatures range from 9000 to 30 000K during the machine on time, and they depend upon the type of dielectric used, i.e., 20 850K for water and 17 175K for hydrocarbon oil. There are two distinct layers: the white or recast layer and the heat-affected zone at the surface of workpiece machined by EDM [66]. The formation of the two layers and the related mechanical properties depend upon the type of the dielectric used. Since chemical compositions and thermal conductivities of water-based dielectrics and hydrocarbon oils are different. Kruth et al. [67] reported that the white layers of $C 35$ steel had a carbon about four times more than the base material when machined in a hydrocarbon oil while; carbon content decreases nearly $50 \%$ of the base material when machined in deionised water. Ogata and Mukoyama [68] carburization occured in the white layer of the workpiece when it was machined with hydrocarbon dielectric and decarburization of the white layer happened when workpiece was machined with deionised water. The regions of carburization were suspected due to thermal decay of the carbon of hydrocarbon oil, resulting in a higher concentration of carbon along the airfoil of the white layer. Decarburization happened when the carbon content of the white layer decreases. The mechanism of decarburization is associated with binding of carbon from workpiece with hydrogen and oxygen of deionised water. Kruth et al. [67] disclose that, numbers of gaps in the white layer of pieces of steel workpiece machined with water are less than the steel workpiece machined with oil. While, Chen et al. [69] proved that when the workpiece of Ti-6Al-4V machined with deionized water, it was observed a bigger number of gaps along the blank layer. Findings suggest that, presence of micro-cracks in the white layer decreases the fatigue strength of the machined components. Kranz et al. [70] performed experimental investigations with commercial water-based dielectric, Elbolub, and a hydrocarbon oil as dielectrics and different tool steels as a workpiece to study the relation between the microstructure of the surface layer, and the corresponding toughness of workpiece machined. Results suggest that for high-strength steels when machined with water-based dielectrics, microstructure combined with cracks, causes a loss of toughness, while machining a lower-strength steels there were no significant changes in tough- ness.

Referable to the thermal decay of the dielectric the EDM process generates gases and exhaust. It was observed that deionized water produces the lowest measure of harmful substances, although benzopyrene and benzene are considered as carcinogenic [12]. Still, some researchers $[72,71]$ suggested that concentrations of both chemicals are more down for the maximum allowable value which is much less hazardous to the operator and to the environment.

\section{Conclusions and Future Scope}

Later a comprehensive exploration of the published research paper, the conclusions drawn are:

Most of the published work focuses on material removal rate, tool wear rate, and surface finish. Further study should concentrate more on developing dry EDM as a precision machining operation. For which supplementing with material removal rate, tool wear rate and surface finish, other performance variables such as over-cut, process repeatability is also needed.

In most of the dry-EDM process, either air or oxygen is used as a dielectric. Further work may explore the purpose of nitrogen and inert gases as a dielectric. Nitrogen might be helpful if surface treatments such as nitriding are required as postmachining. However, helium has a relatively very high-heat capacity and may provide better performance in terms of precision of the cut.

Not a lot study has been taken out in terms of applications of dry EDM process in micromachining; apart from drilling deep holes application of DEDM in macro-scales is much restricted. Further research work is necessitated at the micro-level to make dry electric discharge micro machining feasible.

Hybrid micromachining has a capability to incorporate the military posture and the weakness of different operations; a newer hybrid micromachining technology is pivotal to rectify various drawbacks faced in conventional as well as gas based EDM process.

The development of dry and near-dry EDM technique focused much on to increase the MRR since the MRR is lower compared to conventional EDM machining. Very few studies reported surface integrity of machined parts. In summation, an analysis and quantification of other features on dry EDMed surface such as porosities, dimples 
and river lines and analytical modeling of the phenomenon of crack formation on dry EDMed surfaces all needed to be taken as a fruitful future work.

Current literature is deficient relative to theoretical modeling and process simulation, such as finite-element analysis in dry EDM. In order to analyze the effect of the gaseous dielectric existing oil EDM theory and simulation models may be modified. From literature review, it was observed that until the date, no work reported on modeling and optimization using a hybrid approach in case of dry EDM machining. In order to understand the fluid dynamics of the dielectric gas flow through the inter-electrode gap and its effect on performance of process further work are much required.

Very few works reported dry EDM, milling process. So Dry EDM, milling characteristics may be investigated by implementing $X-Y$ table movement. Complex two or two and a half dimensional parts may be machined using the dry EDM milling process. Future research in addition to MRR, the stability, surface integrity and accuracy of the milling process all need to be reconsidered. Prospective research should be focused through the use of low discharge energy in case of near-dry EDM to generate fine surface finish.

Most of the literatures reported uses of alloy steel as the workpiece, while fewer studies were carried out on $\mathrm{SiC}$ and $\mathrm{Al}_{2} \mathrm{O}_{3}$ reinforced metal matrix composites. Limited work has been reported on electro-conductive ceramic and other MMCs types, the use of pure water or water emulsion as a dielectric fluid for machining metal matrix composite (MMC).

Individual work is reported on the utilization of powder mixed near dry EDM, powders like manganese, chromium, molybdenum, and vanadium may be examined in case of near dry EDM process.

Most research work centered on a non-electrical parameter like tool rotation and flushing pressure, whereas limited works had been reported on work piece rotation and oscillation. Few subjects have found alterations in mechanical properties of dry and near dry-EDM work component. Cryogenically cooled work pieces, also witnessed one-study. Future investigations may consider cryogenically cooled tool, machining parameters, and optimal cryogenic temperature, among others, as far as
EDM machining performance is seen.

The scanning tunneling microscope platform and pulse generator can collaborate for successful nano-EDM of harder materials or even a metal matrix composite.

Under specific machining conditions, a mixture of gases and organic deionize water may make a higher material removal rate than hydrocarbon oil. This particular approach needs further investigations for before initiating commercial use.

\section{References and Notes}

[1] Ho, K.H., Newman, S.T., (2003), State of the art electrical discharge machining (EDM), International Journal of Machine Tools \& Manufacture, 43, pp. 1287-1300

[2] Sanjeev Kumar et al. (2012), Electric discharge machining of titanium and its alloys: a review, international journal of Machining and Machinability of Materials

[3] Abbas, N. M., Solomon, D. G., and Bahari, M. F., (2007), A review on current research trends in electrical discharge machining (EDM), International Journal of Machine Tools \& Manufacture, Vol. 47, 2007,pp. 1214-1228.

[4] Pandit, S.M., and. Rajurkar, K.P., (1981), Analysis of electro discharge machining of cemented carbides, Annals of the CIRP, 30 (1), pp. 111-116.

[5] Li, M.H., (1989), The Theoretical Bases of Electrical Discharge Machining, Defense Industry Press, Beijing, (in Chinese).

[6] Hoh, S., (1963), Mechanism of EDM. JSPE. 29. 10. 11 -1 6 (in Japanese).

[7] Konig, W., and Siebers, F.J., (1993), Influence of the Working Medium on the Removal Process in EDM Sinking, ASME PED-Vol.64, pp. 649-656.

[8] Eckman, P.K., and Williams, E.M., (1960), Plasma Dynamics in an Arc Formed by Low-Voltage Spark over of a Liquid Dielectric, Applied Scientific Research, Section 6, 8, pp. 299320

[9] Zolotykh, S.N., (1959)'The Mechanism of Electrical Erosion of Metals in Liquid Dielectric Media, Soviet Phys. Tech. Phys. 4, 12, pp.1370-1373.

[10] Han, F., and Kunieda, M., (2004), Development of parallel spark electrical discharge machining, Precision Engineering 28, pp. 65-72.

[11] Leao, F. N. and Pashby, I. R. (2004), A review on the use on environmentally-friendly dielectric fluids in electrical discharge machining, Journal of Material Processing Technology, Vol. 149, Issues 1-3, pp. 341-346.

[12] Besliu, Irina et al., (2010), study of dry electrical discharge machining, International Journal of Material Forming. Vol. 3 Suppl (1) pp.1107-1110.

[13] Ramani, V. and Cassidenti, M.L., (1985), Inert-Gas Electrical- 
Discharge Machining. NASA Technical Brief No. NPO-15660.

[14] Kuineda, M. et al., (1991) Improvement of EDM Efficiency by Supplying Oxygen Gas into Gap. CIRP AnnalsManufacturing Technology, Vol. (40), pp. 215-218.

[15] Kuineda, M. and Yoshida, M., (1997), Electrical discharge machining in gas, CIRPAnnals-Manufacturing. Technology, Vol. (46), pp. 143-146.

[16] Skrabalak, G., and Kozak, J., (2010), Study on Dry Electrical Discharge Machining, Proceedings of the World Congress on Engineering Vol (III) WCE 2010, June 30 - July 2, 2010, London, U.K.

[17] Besliu, I., and Coteata, M., (2009), Characteristics of the dry electrical discharge machining, Nonconventional Technologies Review - no. 2/2009

[18] Yoshida, M., and Kunieda, M., (1999), Study on mechanism for minute tool electrode wear in dry EDM, Seimitsu Kogaku Kaishi/Journal of the Japan Society for Precision Engineering 65. pp. 689-693.

[19] Zhanbo, Y., Takahashi, J., Nakajima, N., Sano, S., Karato, K., and Kunieda, M., (2005), Feasibility of 3-D surface machining by dry EDM, International Journal of Electrical Machining. Vol. (10), pp.15-20.

[20] Yu et al., (2004), Dry electrical discharge machining of cemented carbide, Journal of Material processing Technology, 14th International Symposium on Electro machining (ISMEXIV), Vol. (149), PP. 353-357.

[21] Zhang, Q.H., Zhang, J.H., Deng, J.X., and Niu, Z.W., (2002), Ultrasonic vibration in electrical discharge machining in gas, Journal of Materials Process and Technology, Vol. (129), pp. 135-138.

[22] Zhang, Q.H., Zhang, J.H., and Zhang, Q.B., (2006), An Investigation of ultrasonic-assisted electrical discharge machining in gas, International Journal of Machine Tools \& Manufacture, Vol. (46), pp. 1582-1588.

[23] Saha, S.K., and Choudhury, S.K., (2009), Experimental investigation and empirical modeling of the dry electric discharge machining process, International Journal of Machine Tools and Manufacture, Vol. (49), pp. 297-308.

[24] Xu et al., (2009), Material removal mechanisms of cemented carbides machined by ultrasonic vibration assisted EDM in gas medium, Journal of materials processing technology, pp. $1742-1746$.

[25] Govindan, P., Joshi, S., (2011), Investigations into Performance of Dry EDM Using Slotted Electrodes, International journal of precision Engineering and Manufacturing, Vol. (12), No. 6, pp. 957-963.

[26] Kunieda, M., Takaya, T., and Nakano, S., (2004), Improvement of dry EDM characteristics using piezoelectric actuator, CIRP Annals-Manufacturing Technology, 53, pp. 183-186.

[27] Roth, R., et al., (2013), Influence of oxidizing gas on the stability of dry electrical discharge machining process, Procedia CIRP 6, 339 - 344

[28] Roth, R., et al., (2012), Influence of the Anode Material on the Breakdown Behavior in Dry Electrical Discharge Machining, Procedia CIRP, Vol. (1) pp. $639-644$.

[29] Govindan, P., et al., (2010), Experimental characterization of material removal in dry electrical discharge drilling, International Journal of Machine Tools \& Manufacture, Vol. (50) pp. 431-443.

[30] Li et al., (2004), Discussion of electrical discharge machining in gas, The 31st IEEE International conference on plasma science, ISBN:0-7803-8334-6

[31] Zhang, L. Q., et al., (2004), Discussion of electrical discharge machining in gas. The 31st IEEE International Conference on Plasma Science, ICOPS. IEEE Conference Record.

[32] Curodeau, A., Richard, M., and Frohn-Villeneuve, L., (2004), Molds surface finishing with new EDM process in air with thermoplastic composite electrodes, Journal of Materials Processing Technology, Vol. (149), pp. 278-283.

[33] Joshi, S. et al., (2011), Experimental characterization of dry EDM performed in a pulsating magnetic field, CIRP Annals Manufacturing Technology, Vol. (60), pp. 239-242.

[34] Umbrello, et al., (2012), Analysis of the white layers formed during machining of hardened AISI 52100 steel under dry and cryogenic cooling conditions, International Journal of Advanced Manufacturing Technology.

[35] Govindan, P. and Joshi, Suhas. S., (2012), Analysis of microcracks on machined surfaces in dry electrical discharge machining, Journal of Manufacturing Processes, 14, pp. 277-288.

[36] Teimouri, Reza and Baseri, Hamid., (2012), Improvement of dry EDM process characteristics using artificial soft computing methodologies, Prod. Eng. Res. Devel. 6. pp.493-504.

[37] Kunieda, M., Miyoshi, Y., Takaya, T., Nakajima, N., Bo, Y.Z. and Yoshida, M., (2003), High speed 3D milling by dry EDM, CIRP Annals Manufacturing Technology, 52, pp. 147-150.

[38] Skrabalak, G. et al., (2013), Optimization of Dry EDM process, Procedia CIRP 6, pp.333-338.

[39] Hu, D.J., (2010), Experimental investigations into neardry milling EDM of Stellite alloys, Int. J. Machining and Machinability of Materials, Vol. 7, Nos. 1/2.

[40] Kao, C. C. et al., (2007), Near-dry electrical discharge machining (EDM) process, International Journal of Machine Tools \& Manufacture, 47, pp. 2273-2281.

[41] Tao, Jia et al., (2007), Near-Dry EDM Milling of Mirror-Like Surface Finish, International Journal of Electrical Machining, No.13, January 2008.

[42] Tao, Jia et al., (2008), Experimental Study of the Dry and Near-Dry Electrical Discharge Milling Processes, Journal 
of Manufacturing Science and Engineering, Vol. (130), pp. 011002-1.

[43] Liquing, Li et al., (2011), Research on Dry EDM Processing Performance with Two Kinds of Pulse Generator Modes, ASME International Manufacturing Science and Engineering Conference, Volume (1) Corvallis, Oregon, USA, June 13-17, 2011.

[44] Masahiro, Fujiki et al., (2011), Gap control for near-dry EDM milling with lead angle, International Journal of Machine Tools and Manufactur, Vol. (10), pp.77-83.

[45] Masahiro, Fujiki et al., (2011), Tool Path Planning for Near-Dry EDM Milling with Lead Angle on Curved Surfaces, Journal of Manufacturing Science and Engineering, Vol.(133) pp.051005-1.

[46] Liqing, L. and Yingjie, S., (2013), study of dry EDM with oxygen mixed and cryogenic cooling approaches, Procedia CIRP, 6, pp. 345-351.

[47] Malshe, A. P., et al., (2012), Experimental investigation and characterization of a novel technique of nanoscale dry electro-machining, Journal of Manufacturing Processes, Vol. (14), pp.443-451.

[48] Malshe, A. P. et al., (2013), A comparative study of the dry and wet nano-scale electro-machining, Procedia CIRP, 6, pp. 627-632.

[49] Zhang, Q. H. et al., (2013), Research on material removal rate of powder mixed near dry electrical discharge machining, Int. J. Adv. Manuf. Technol., August 2012.

[50] Garg, R.K. et al., (2010), Review of research work in sinking EDM and WEDM on metal matrix composite materials, International Journal of Advanced Manufacturing Technology, pp. 611-624.

[51] Erden, A., and Temel, D., (1981), Investigation on the use of water as a dielectric liquid in electric discharge machining, in: Proceedings of the 22nd Machine Tool Design and Research Conference, Manchester, pp. 437-440.

[52] Jeswani, M.L., (1981), Electrical discharge machining in distilled water, International Journal of Wear, Vol. 72, pp.8188.

[53] Tariq, S. Jilani., Pandey, P.C., (1984), Experimental investigations into the performance of water as dielectric in EDM, International Journal of Machine Tool Design and Research, Vol. 24, pp. 31-43.

[54] Koenig, W., Joerres, L., (1987), An aqueous solution, CIRP Annals-Manufacturing Technology, Vol. 36, pp. 105-109.

[55] Konig, W., Siebers, F. J., (1993), Influence of the working medium on the removal process in EDM sinking, American Society of Mechanical Engineers, Production Engineering Division (Publication) PED, Vol. 64, pp. 649-658.

[56] Konig, W., Klocke, F., and Sparrer, M., (1995) EDM—sinking using water-based dielectrics and electropolishing - a new manufacturing sequence in tool-making, in: Proceedings of the 11th International Symposium on Electromachining (ISEM XI), Lausanne, Switzerland, 1995, pp. 225-234.

[57] Masuzawa, T., Tanaka, K., and Nakamura, Y., (1983), Waterbased dielectric solution for EDM, Ann. CIRP, 32, pp. 119122.

[58] Masuzawa, T., (1981), Machining characteristics of EDM using water as dielectric fluid, in: Proceedings of the 22nd Machine Tool Design and Research Conference, Manchester, pp. 441-447.

[59] Yonghong, Liu et al., (2012), Die-sinking electrical discharge machining with oxygen-mixed water-in-oil emulsion working fluid, Proceedings of the Institution of Mechanical Engineers, Part B: Journal of Engineering Manufacture November 20, 2012.

[60] Yonghong, Liu et al., (2013), Experimental Characterization of Sinking Electrical Discharge Machining Using Water in Oil Emulsion as Dielectric, Materials and Manufacturing Processes, Volume 28, Issue 4.

[61] Medellin, H. I., et al., (2009), Experimental study on electrodischarge machining in water of D2 tool steel using two different electrode materials, Proceedings of the Institution of Mechanical Engineers, Part B: Journal of Engineering Manufacture, vol. 223 pp. 111423-1430.

[62] Dunnebacke, G., (1992), High performance electrical discharge machining using a water-based dielectric, in: Proceedings of the 10th International Symposium for Electro machining (ISEM X), Magdeburg, Germany, pp. 170182.

[63] Dewes, R., Aspinwall, D., Burrows, J., Paul, M., and ElMenshawy, F., (2001), High speed machining-multi-function/ hybrid systems, in: Proceedings of the Fourth International Conference on Industrial Tooling, Southampton, UK, pp. 91-100.

[64] Karasawa, T., and Kunieda, M., (1990), EDM capability with poured dielectric fluids without a tub Bull, Jpn. Soc. Precision Eng. 24, pp. 217-218.

[65] Pillans, B.W., Evensen, M. H., Taylor, H.F. and Eubank, P.T., (2002), Fiber optic diagnostic techniques applied to electrical discharge machining sparks, J. Appl. Phys. 91, pp. 1780-1786.

[66] Mc Geough, J. A., (1988), Advanced Methods of Machining, Chapman \& Hall, London, ISBN 0412319705.

[67] Kruth, J. P., Stevens, L., Froyen, L., Lauwers, B., Leuven, K.U., (1995), Study of the white layer of a surface machined by die-sinking electrodischarge machining, Ann. CIRP, 44, pp. 169-172.

[68] Ogata, I., and Mukoyama, Y., (1993), Carburizing and decarburizing phenomena in EDMed surface, Int. J. Jpn. Soc. Precision Eng. 27, pp.197-202. 
[69] Chen, S.L., Yan, B.H., and Huang, F.Y., (1999), Influence of kerosene and distilled water as dielectric on the electric discharge machining characteristics of Ti-6Al-4V, Journal of Materials Processing Technology, Vol. 87, pp. 107-111.

[70] Kranz, R., Wendl, F., and Wupper, K. D., (1990), Influence of EDM conditions on the toughness of tool steels, Thyssen Edelstahl Technische Berichte, pp.100-105.

[71] Evertz, S., Eisentraeger, A., Dotti, W., Klocke, F., Karden, A., and Antonoglou, G., (2001), Environmental and industrial hygiene in connection with electrical discharge machining at high discharge energies, in: Proceedings of the 13th International Symposium on Electro machining (ISEM XIII), vol. I, pp. 193-210.

[72] Bommeli, B., (1983), Study of the harmful emanations resulting from the machining by electro-erosion, in: Proceedings of the Seventh International Symposium on Electro machining (ISEM VII), pp. 469-478. 